\section{Álcool e violência: a psiquiatria e a saúde pública}

\author{
Alcohol and violence:
} psychiatry and public health
A relação entre violência e o consumo de bebidas alcoólicas é complexa. No entanto, mesmo sem existir uma relação causal simples e unidirecional, vários modelos teóricos são propostos para entender este fenômeno, dentre os quais podemos citar três: 1) o uso do álcool conduziria ao crime; 2) o crime conduziria ao uso de álcool; 3) a relação seria coincidente ou explicada por uma associação de causas comuns. ${ }^{1}$

No primeiro modelo, o álcool levaria ao crime principalmente por suas propriedades psicofarmacológicas. Do ponto de vista biológico, alguns efeitos da intoxicação alcoólica incluindo distorção cognitiva e de percepção, déficit de atenção, julgamento errado de uma situação e mudanças neuroquímicas - poderiam originar ou estimular comportamentos violentos. A intoxicação crônica pode contribuir com agressões por fatores como privação de sono, abstinência, prejuízo de funcionamento neuropsicológico ou associação com transtornos de personalidade.

O segundo modelo explicaria melhor a relação entre crimes e drogas ilícitas, podendo ser aplicado ao álcool. Está baseado na suposição de que os indivíduos que cometem crimes são mais provavelmente expostos a situações socioculturais e ambientais onde o beber pesado é perdoado ou encorajado. Desta forma, estudos experimentais relatam que, em ambientes onde existirem maior expectativa de aceitação da violência e menor receio das suas conseqüências sociais, físicas e legais, teríamos um maior índice de criminalidade e abuso de substâncias psicoativas.

O terceiro modelo pressupõe que a relação bebida-violência seja devida a causas comuns, dentre as quais figurariam a personalidade, antecedentes familiares de alcoolismo, fatores genéticos, características de temperamento, pobre relacionamento com os pais, transtorno de personalidade anti-social e todas as circunstâncias sociais que predisporiam ao crime e à bebida.

As relações são múltiplas e variadas, mas o consumo de álcool é, no mínimo, um importante facilitador de situações de violência. Não faltam evidências científicas de sua participação nos homicídios, suicídios, violência doméstica, crimes sexuais, atropelamentos e acidentes envolvendo motoristas alcoolizados.

Estatísticas internacionais apontam que em cerca de 15\% a $66 \%{ }^{1}$ de todos os homicídios e agressões sérias, o agressor, vítima, ou ambos tinham ingerido bebidas alcoólicas. Da mesma maneira, o consumo de álcool está presente em cerca de $13 \%$ a $50 \%^{2}$ dos casos de estupro e atentados ao pudor. No Brasil, dados do Cebrid ${ }^{3}$ apontam que $52 \%$ dos casos de violência doméstica estavam ligados ao álcool.

Se a existência de uma relação entre álcool e violência está bem estabelecida, o que fazer do lado preventivo? Um dos caminhos mais efetivos é o proposto por pesquisadores como Holder, citado no mais recente consenso sobre as políticas do álcool produzido pela Organização Mundial de Saúde (OMS). ${ }^{2}$ Ele desenvolveu um modelo amplamente aceito em que intervenções ambientais seriam mais efetivas que políticas voltadas ao indivíduos (por exemplo, prevenção em escolas). Assim, com o controle sobre o preço de bebidas alcoólicas e seus pontos de venda, controle sobre os produtos a serem 
vendidos, evitando-se as promoções e publicidade, teríamos estratégias poderosas para a redução dos problemas relacionados ao álcool.

Recentemente, uma cidade brasileira está colocando em prática e comprovando os conceitos acima. Diadema, a cidade brasileira com o maior número de assassinatos em 1999 (por 100.000 habitantes), após mapeamento da criminalidade local, verificou que $65 \%$ destes ocorriam próximos ou no interior dos bares e ligados a motivos fúteis. Em julho de 2002, adotou uma política de fechamento de bares às 23 horas. Interessantemente, essa medida está prevenindo homicídios. Modelos logarítmicolineares que avaliam o impacto desta intervenção demonstraram que, após a limitação dos horários de venda de álcool, preveniuse 273 assassinatos nos 24 meses de sua vigência, ou uma média de 11 assassinatos por mês. Quanto ao impacto sobre os índices de violência contra as mulheres, houve uma redução de nove agressões por mês, representando $40 \%$ de queda neste tipo de ocorrência em dois anos.

Os resultados de Diadema provêem evidência importante de que esta relação (álcool-violência) não tem que ser aceita necessariamente como imutável e que a tomada de decisões de políticas públicas utilizando-se de evidências científicas é possível e extremamente benéfica. Ao contrário do que muitos pensam em relação ao caráter do brasileiro, uma medida restritiva, associada a uma fiscalização diária e efetiva, conseguiu ser obedecida e popular com $92 \%$ de aprovação, dois anos após a implementação da lei.

Um grupo de psiquiatras e psicólogos, representando a Associação Brasileira de Psiquiatria (ABP) e a Associação Brasileira de Estudos do Álcool e outras Drogas (ABEAD), publicou, em 2004, o primeiro consenso brasileiro sobre políticas públicas em relação ao álcool. ${ }^{4}$ Uma das principais conclusões foi a de que é possível desenvolver estratégias que influenciem tanto a quantidade de álcool consumida, quanto os comportamentos de consumo e os contextos de alto risco causadores dos problemas relacionados ao consumo de álcool em uma comunidade.

Diante destes argumentos e formas de modelos, é razoável argumentar que temos opções de intervenções que reduzem muito a ligação entre álcool e violência. O que os profissionais responsáveis pela saúde pública necessitam é escolher as opções mais adequadas e que tenham o melhor custo benefício para a sociedade.

\section{Ronaldo Laranjeira, Sérgio Marfiglia Duailibi,} Ilana Pinsky

Unidade de Pesquisa em Álcool e outras Drogas (UNIAD), Universidade Federal de São Paulo (UNIFESP), São Paulo (SP), Brasil Departamento de Psiquiatria, Universidade Federal de São Paulo (UNIFESP), São Paulo (SP), Brasil

\section{Referências}

1. White HR, Gorman DM. Dynamics of the drugs-crime relationship. In: Lafree G, editor. Criminal justice 2000: The nature of crime: continuity and change. Washington, DC: National Institute of Justice;2000. v. 1 p. 151-218.

2. Babor TF, Caetano R, Caswell S, Edwards G, Giesbrech N, Grahan K, et al. The global burden of alcohol consumption. In: Babor TF, Caetano R, Caswell S, Edwards G, Giesbrech N, Grahan K, et al Alcohol: no ordinary commodity: Research and public policy. Oxford: Oxford University Press; 2003. p. 57-92.

3. Carlini EA, Galduróz JCF, Noto AR, Nappo SA. I Levantamento domiciliar sobre o uso de drogas no Brasil: estudo envolvendo as 107 maiores cidades do país - 2001. São Paulo: CEBRID - Centro Brasileiro de Informações Sobre Drogas Psicotrópicas: UNIFESP - Universidade Federal de São Paulo; 2002. p. 480-2.

4. Laranjeira R, Romano M. Consenso brasileiro sobre políticas públicas do álcool. Rev Bras Psiquiatr. 2004;26 Suppl 1:68-77. 